Supporting Information for:

\title{
Quantification of gas-wall partitioning in Teflon environmental chambers using rapid bursts of low-volatility oxidized species generated in-situ
}

Jordan E. Krechmer $^{\dagger, \dagger}$, Demetrios Pagonis ${ }^{\dagger, \dagger}$, Paul J. Ziemann ${ }^{\dagger, \dagger}$, Jose L. Jimenez ${ }^{\dagger, t, *}$

${ }^{\dagger}$ Cooperative Institute for Research in Environmental Sciences (CIRES), Boulder, CO, 80309, USA

${ }^{ \pm}$Department of Chemistry and Biochemistry, University of Colorado, Boulder, CO, 80309, USA

\section{Corresponding Author:}

*Jose-Luis Jimenez

University of Colorado; UCB 216, Boulder, CO 80309-0216

Phone: 303-492-3557

Fax: 303-492-1149

jose.jimenez@colorado.edu

This file includes:

Pages S1-S19

Materials and Methods

Figs. S1-S11

Tables. S1-S2

References 


\section{Materials and Methods:}

\section{Quantification of active and passive chamber mixing timescales for an inert tracer. Herein,}

we describe a procedure for determining the mixing timescales of an environmental chamber and its results. We used an LI-840A (LI-COR, Lincoln, Nebraska, USA) non-dispersive infrared $\mathrm{CO}_{2}$ analyzer to measure sudden changes in the concentration of $\mathrm{CO}_{2}$ in the chamber following rapid injections of a $\mathrm{CO}_{2}$ standard gas. $\mathrm{CO}_{2}$ data were acquired at a rate of $1 \mathrm{~Hz}$, which was necessary to visibly observe the rapidly changing concentrations involved in measuring the active mixed timescale.

To measure the active mixing timescale, a set quantity of $\mathrm{CO}_{2}$ was injected from a cylinder via a glass bulb. The exact quantity of $\mathrm{CO}_{2}$ is unimportant; it is only necessary that the injected quantity be significantly higher than the concentration in the chamber and that it is injected quickly through a single chamber port. A small Teflon-coated fan was then turned on inside the bag. The fan creates eddies in the bag, which are visible as variances in the measured $\mathrm{CO}_{2}$ concentration observed by the analyzer. This behavior is shown for four such injections in Figure S1, with the final concentrations subtracted so that the traces lay on top of one another at the end of the experiment. Every trace shows oscillating concentrations for $\sim 15$ seconds, but all four settle down to a stable value after $20 \mathrm{~s}$. This point of stability defines the actively mixed timescale. Note that this should be understood as a $~ 95 \%$ timescale, as opposed to the 1/e (63\%) timescales derived for $\tau_{G W E}$ via fitting, as described on the main text.

The same procedure was followed to measure the passive mixing timescale, when no fan was used. As expected, the passive mixing timescale was much longer ( $700 \mathrm{~s})$ than the actively mixed timescale ( $20 \mathrm{~s})$. The passive timescale mixing traces are shown in Figure $\mathrm{S} 2$ in the same format as Figure S1. 
Correction of $\tau_{G W E}$ for chamber size. This formulation was originally proposed by McMurry and Grosjean ${ }^{1}$ and parameterized by Palm et al., ${ }^{2}$ as follows:

$$
\frac{1}{\tau_{\text {cond }}}=\frac{k_{\text {cond }}}{0.59}=\frac{A}{V} \frac{2}{\pi} \sqrt{k_{e} D}
$$

where $\mathrm{A}(\mathrm{V})$ is the chamber surface area (volume), $D$ is the coefficient of molecular diffusion (here: $7 \times 10^{-6} \mathrm{~m}^{2} \mathrm{~s}^{-1}$ ), and $\mathrm{k}_{\mathrm{e}}$ is the coefficient of eddy diffusion, represented as a chamber volume-dependent function: ${ }^{2}$

$$
k_{e}=0.004+\left(5.6 \times 10^{-3}\right)(V)^{0.74}
$$

where $V$ is the chamber volume in $\mathrm{m}^{3}$. We add a scaling factor of 0.59 to the value of $\tau_{\text {cond }}$ determined in Equation 1 to match the observed average timescale from this work (600 s). Equation 1 is plotted in Figure $S 8$ as a function of $A: V$ for a cubic chamber, with the Caltech chamber and the chamber used in this work highlighted.

Note that the chamber size correction supplied in Equation (1) depends on the wall mass accommodation coefficient of organic vapors, $\alpha$, being larger than $\sim 6 \times 10^{-6}$. In the case where $\alpha$ is much smaller, then the following equation applies ${ }^{1}$ :

$$
\left(\frac{A}{V}\right)\left(\frac{\alpha_{w, i} \bar{C}_{l}}{4}\right)=-k_{\text {cond }}
$$

In cases of intermediate $\alpha$, the full equation should be used ${ }^{1}$ :

$$
\frac{d C_{v, i}}{d t}=\left(\frac{A}{V}\right)\left(\frac{\alpha_{w, i} \bar{C}_{i} / 4}{\frac{\pi \alpha_{w, i} \bar{C}_{i}}{\left(D_{i} K_{e}\right)^{\frac{1}{2}}}}\right) \bar{C}_{v, i}=-k_{c o n d} \bar{C}_{v, i}
$$

The evaporation rate can be calculated from the following expression ${ }^{3}$ :

$$
k_{\text {evap }}=k_{\text {cond }} \frac{C^{*}}{C_{w}}
$$

while noting that the following expression also applies ${ }^{3}$ :

$$
\tau_{\text {gwe }}=\frac{1}{k_{\text {cond }}+k_{\text {evap }}}
$$


Estimate of physical thickness of wall mass concentration $\left(\boldsymbol{C}_{\boldsymbol{w}}\right)$. Here, we provide an estimate of the thickness of FEP chamber surface necessary to account for an equivalent wall mass concentration $\left(C_{w}\right)$ similar to the values determined in this study. The surface area of the bag used in these experiments is $24 \mathrm{~m}^{3}$ and its volume is $8 \mathrm{~m}^{3}$. The density of FEP is reported to be $2.2 \mathrm{~g} \mathrm{~cm}^{-3} \cdot{ }^{4}$ Using a $\mathrm{C}_{\mathrm{w}}$ of $10 \mathrm{mg} \mathrm{m}^{-3}$ in the following equation:

$$
T=\frac{C_{w} V}{A \rho_{w}}
$$

where $\mathrm{V}$ is the volume of the bag, $\mathrm{A}$ is the surface area of the chamber walls and $\rho$ is the density of Teflon, we obtain an equivalent thickness value $(T)$ of $1.5 \mathrm{~nm}$.

This estimate is only provided for reference, as the physical details of the roughness and depth of Teflon film that may be interacting with the gas-phase are not well understood (see main text).

Estimate of physical thickness due to particle deposition to chamber walls. Here, we provide an estimate of the thickness of material buildup on chamber walls due to particle deposition during SOA experiments. We assume 2 years before FEP bag replacement and an average of 3 experiments per week. We use $1.3 \mathrm{~g} \mathrm{~m}^{-3}$ as a typical material density for chamber SOA. ${ }^{5}$ We use this equation:

$$
T=f_{w} \frac{C_{S O A} V}{A \rho_{S O A}}
$$

which is analogous to the previous one. We assume a chamber in which the average experiment produces $300 \mu \mathrm{g} \mathrm{m}^{-3}$ of particles, of which $50 \%$ deposits on the walls $\left(f_{w}=0.5\right)$, with the rest of the particles being either sampled by the instrumentation or exhausted at the end of the experiment. Under those assumptions, the mass of deposited particles accumulated would be equivalent to a $12 \mathrm{~nm}$ thick after 2 years of experiments. For an experimental regime at lower concentrations in which the average experiment produces $3 \mu \mathrm{g} \mathrm{m}^{-3}$ (with all other parameters 
kept constant), the layer of particles would be $0.12 \mathrm{~nm}$ thick after 2 years of experiments. We note that much of the particle material can be removed during chamber cleaning procedures (e.g. continuous flushing with zero air, UV light irradiation, ozone injection, added humidity, and heating), and thus these values represent upper limits.

Estimate of diffusion-limited inlet loss. Wall losses of gas-phase species to inlet walls due to gaseous diffusion were estimated using equations provided in ${ }^{6}$.

The fraction of species penetrating a tube can be expressed by $\eta^{\text {Ref: } 6 \text { : }}$

$$
\eta_{\text {tube }}=\exp [-\xi S h]
$$

where $S h$ is the Sherwood number and is calculated for laminar flow as ${ }^{6}$ :

$$
S h=3.66+\frac{0.2672}{\xi+0.10079 \xi^{1 / 3}}
$$

in which $\xi$ is a dimensionless diffusion parameter ${ }^{6}$ :

$$
\xi=\frac{\pi D L}{Q}
$$

and $D$ is a species diffusion coefficient, $L$ is the tube length, and $Q$ is the volumetric rate of flow through the tube. In this work, we used the online SPARC calculator ${ }^{7,8}$ to calculate a diffusion coefficient for an example molecule. We refer the reader to the literature reference for more detailed information on these calculations. ${ }^{6}$ 


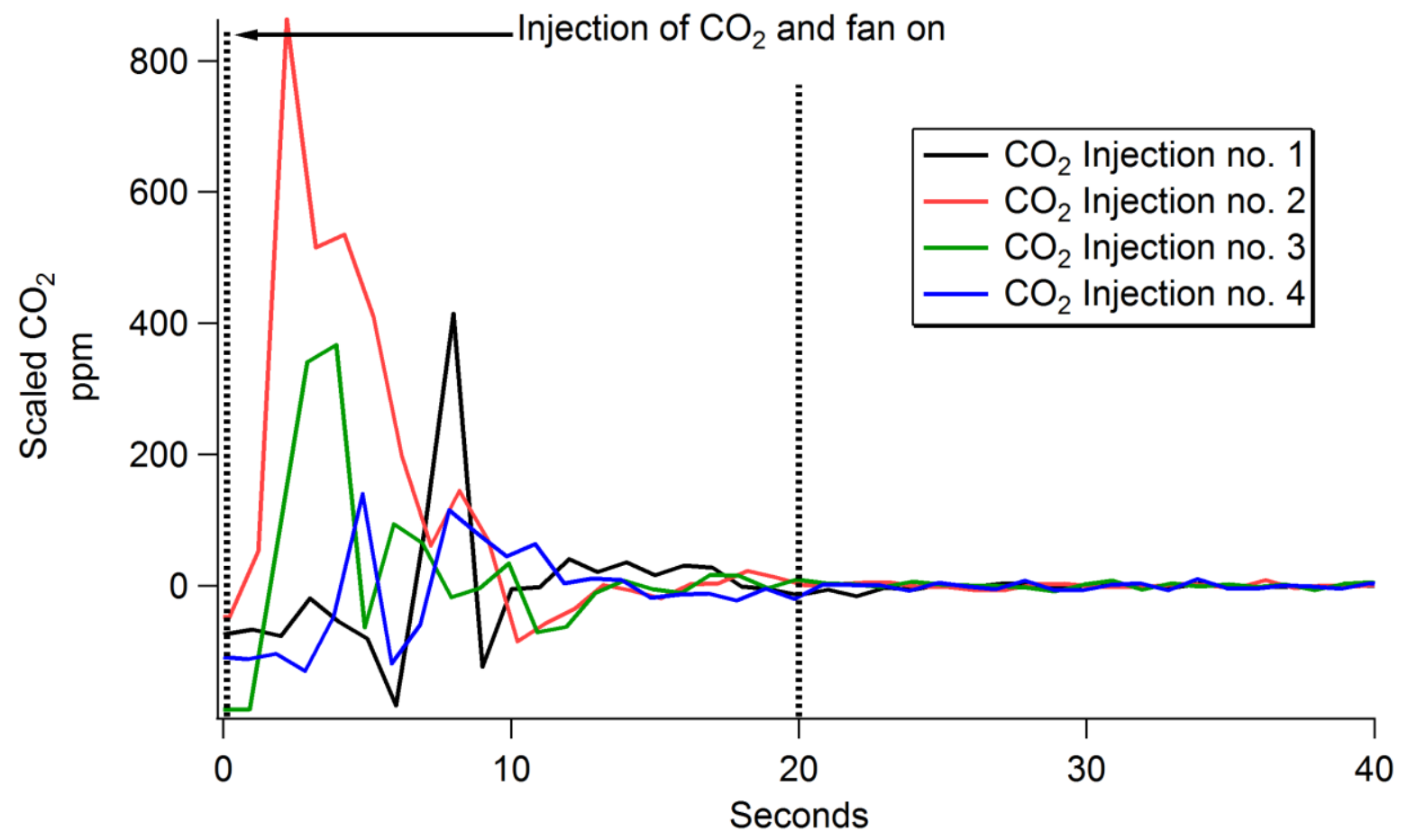

Figure S1. Results of an experiment to determine the active mixing timescale (when using a fan) for our environmental chamber. $\mathrm{CO}_{2}$ time series traces are scaled so that their ending values are the same. The oscillations in the beginning are due to incomplete mixing of $\mathrm{CO}_{2}$ in the bag. The dotted vertical line on the left denotes when the fan was turned on and the one on the right denotes the point at which the chamber is well-mixed (20 s). Note that this should be understood as a $\sim 95 \%$ timescale, as opposed to the $1 / \mathrm{e}(63 \%)$ timescales derived for $\tau_{G W E}$ via fitting, as described on the main text. 


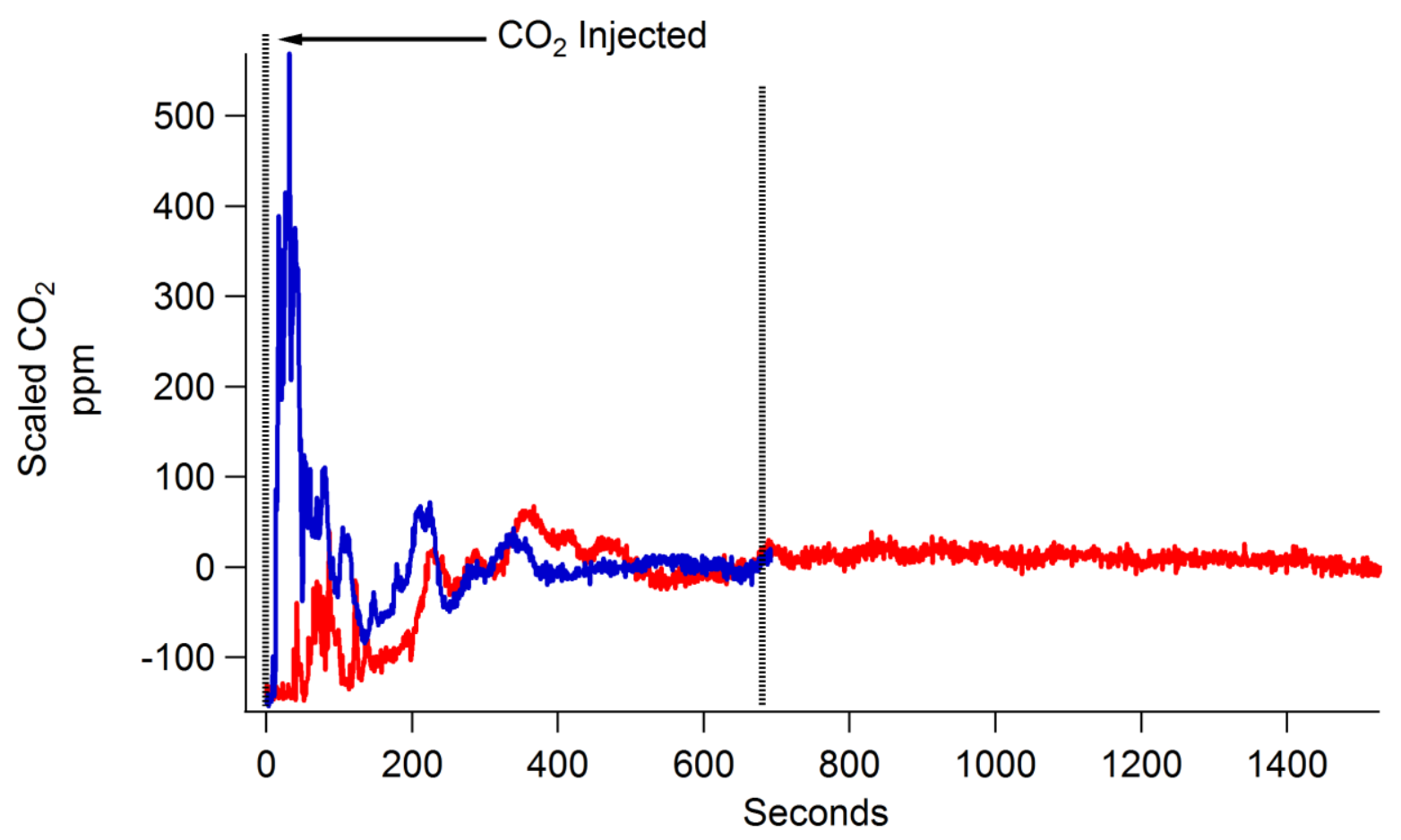

Figure S2. Results of an experiment to determine the passive mixing timescale for our environmental chamber. $\mathrm{CO}_{2}$ time series traces are scaled so that their ending values are the same. The irregular oscillations in the beginning are due to incomplete mixing of $\mathrm{CO}_{2}$ in the bag. The dotted vertical line denotes the point at which the chamber is considered to be well-mixed ( $700 \mathrm{~s})$. Note that this should be understood as a $95 \%$ timescale, as opposed to the $1 / \mathrm{e}(63 \%)$ timescales derived for $\tau_{G W E}$ via fitting, as described on the main text. 

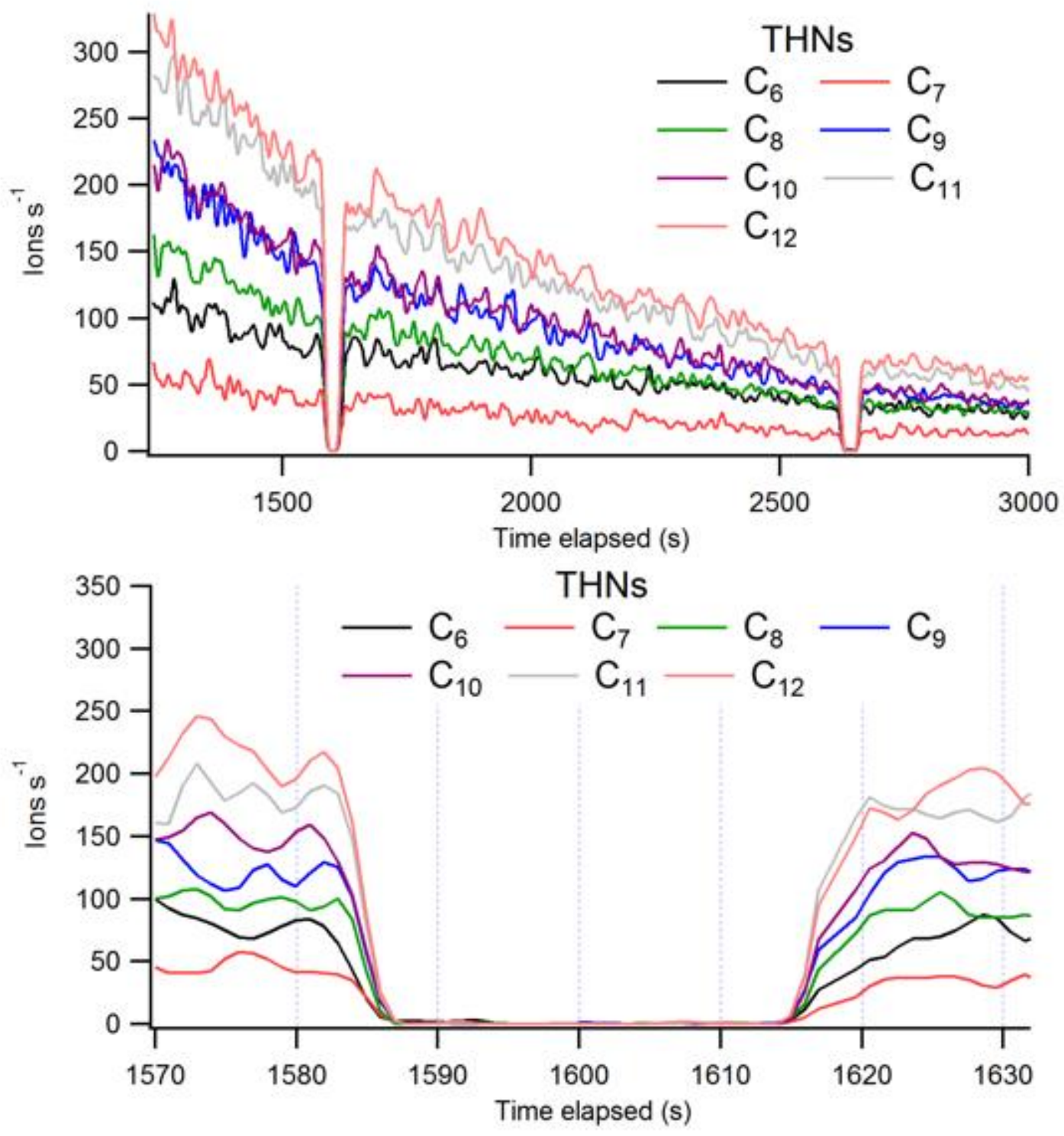

Figure S3: Time series of THNs in which the NO3-CIMS inlet was removed from the chamber and flooded with air from a clean air generator. Two such "zeroing" periods are depicted in the figure. The bottom panel is a zoomed in version of the first "zeroing." The time response of the instrument was $<5 \mathrm{~s}$, which corresponds to the residence time of the inlet and source. 


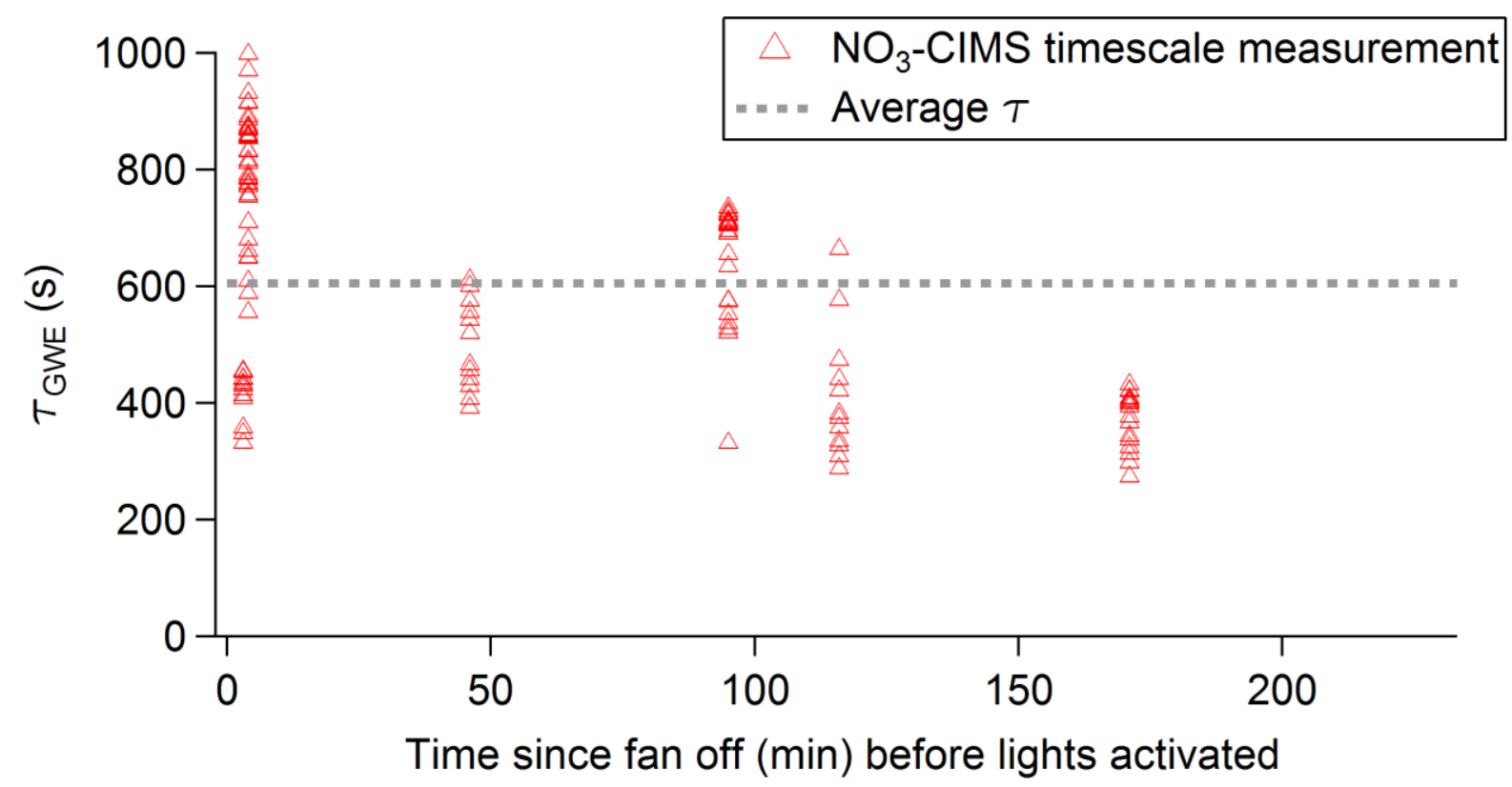

Figure S4. $\tau_{G W E}$ measurements from the $\mathrm{NO}_{3}-\mathrm{CIMS}$ as a function of the time elapsed since the fan was turned off in the chamber. 


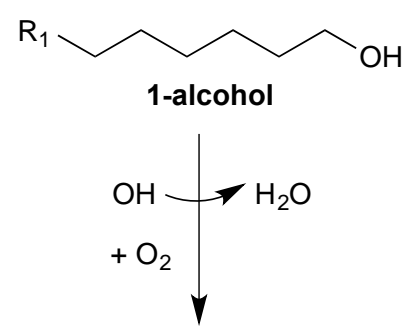

$\mathrm{R}_{1}=\mathrm{R}$ group or $\mathrm{H}$<smiles>[R]CC([O-])CCCCO</smiles>
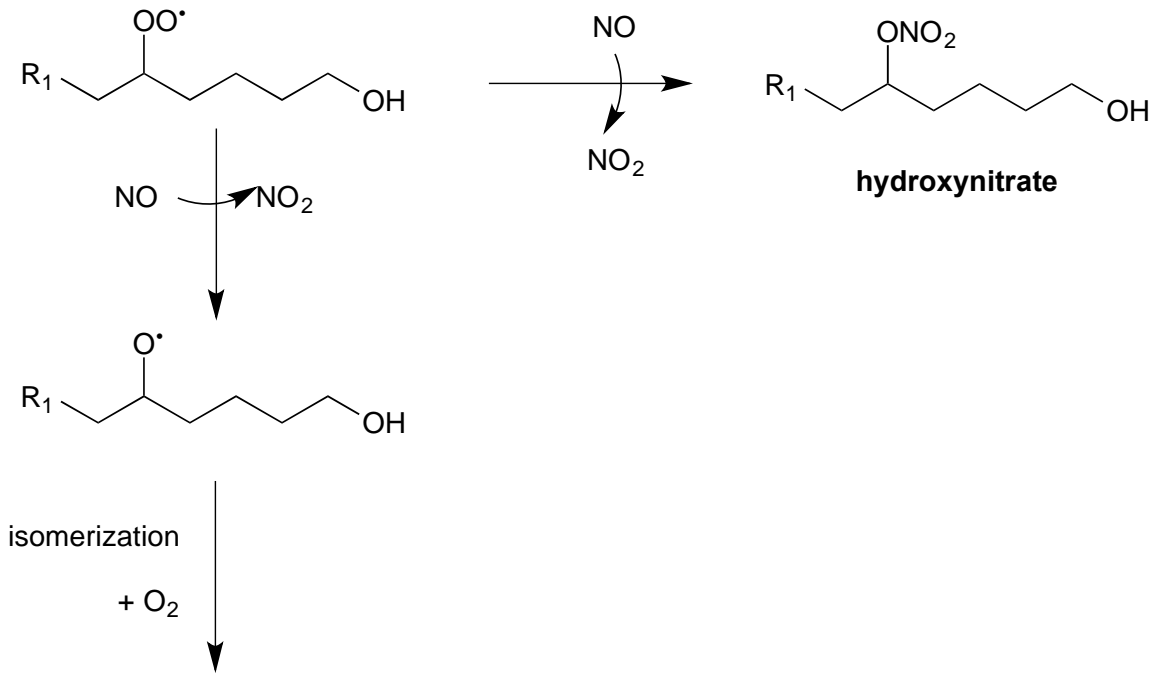<smiles>OCC(O)CCC(O)CBr</smiles>

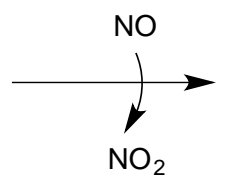<smiles>O=[N+]([O-])C(CO)CCC(O)CBr</smiles><smiles>[R]CC(O)CCC([O])CO</smiles>

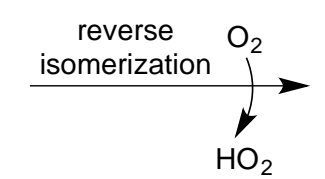<smiles>O=C(CBr)CCC(O)CO</smiles><smiles>[Y][C@H](O)[C@@H](O)CC[C@H](O)CO</smiles><smiles>CC(C)(N=O)[N+](=O)[O-]</smiles><smiles>O=[N+]([O-])OC(Br)C(O)CCC(O)CO</smiles>

trihydroxynitrate

Figure S5. Chemical mechanism for the formation of the oxidized gas-phase products detected in this work. 


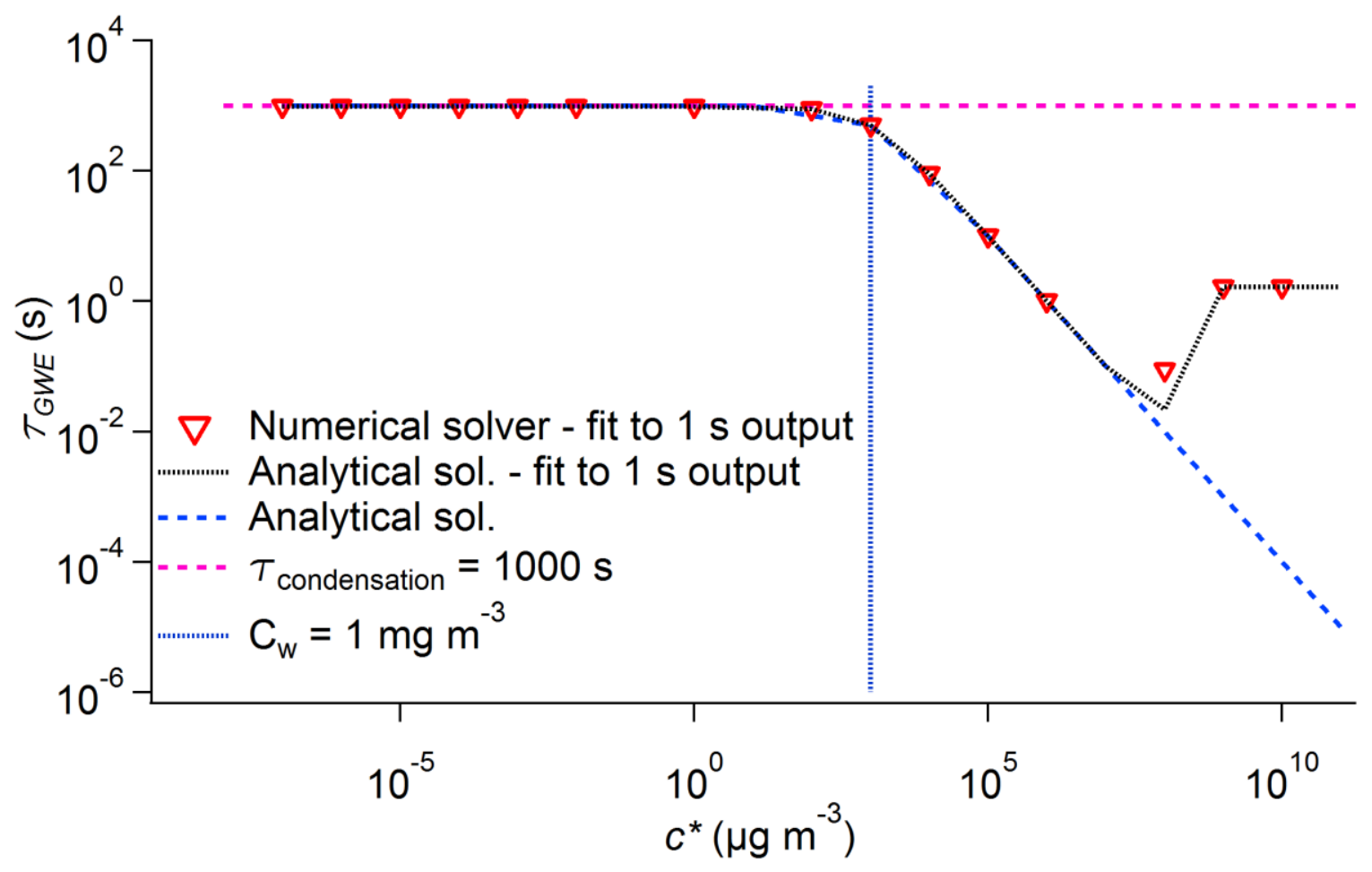

Figure S6. Results of a simple chamber model, in which a single gas-phase species condenses into the wall and evaporates off of it (assuming $C_{w}=1 \mathrm{mg} \mathrm{m}^{-3}$ ). The model was solved analytically and also implemented numerically in the KinSim software within Igor Pro, ${ }^{9}$ which produced consistent results (as shown). The gas-wall equilibrium timescale $(\tau)$ was determined by fitting the model results in a similar way as the experimental data. It is observed that the equilibrium timescale is equal to the condensation timescale (i.e., the inverse of the condensation rate, specified here as $0.001 \mathrm{~s}^{-1}$ ) until the species $c^{*}$ value approaches and exceeds the equivalent wall concentration $\left(C_{w}\right)$. For higher $c^{*}$, most of the species remains in the gas-phase, and thus there is only a very small change due to wall partitioning, and the timescale reaches very low values. When the model output is used with $1 \mathrm{~s}$ time resolution to match the measurements in this work, timescales much shorter than $1 \mathrm{~s}$ cannot be reliably determined with this procedure. This leads to the observed departure between the analytical and fitted results. Note that there is an apparent disagreement between the trend of decreasing $\tau_{\mathrm{GWE}}$ predicted in Fig. S6 at $C^{*}>C_{w}$ and the lack of observation of that trend for the most volatile species (from the Ziemann group) in Figure 3. One plausible explanation for this difference is that the wall accommodation coefficient is $\alpha<<5 \times 10^{-6}$ for the most volatile molecules studied $\left(C^{*} \sim 1 \times 10^{5}-1 \times 10^{6} \mu \mathrm{g} \mathrm{m}^{-3}\right)$ but not for less volatile molecules. This could lead to longer $\tau_{\mathrm{GWE}}$ than predicted in Fig. S6 for those molecules. We note, however, that other explanations may also be possible." 


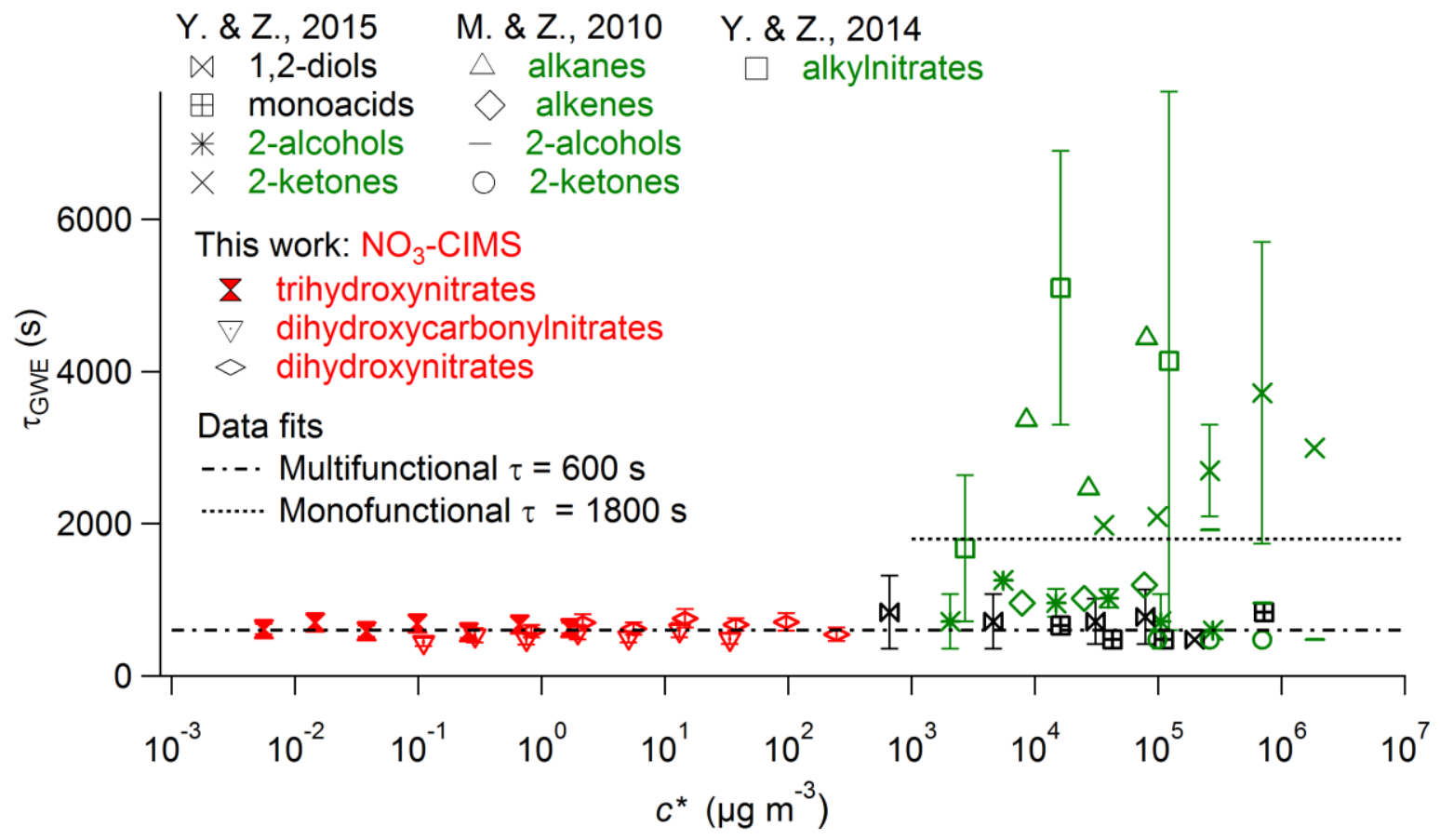

Figure S7. Proposed parameterizations of $\tau_{G W E}$ for use in simulations of chamber experiments. The value of each constant fit is provided in Table 1 . All of these values were obtained in $8 \mathrm{~m}^{3}$ chambers. A correction for chamber size is also shown in Table 1 and Figure S9. 


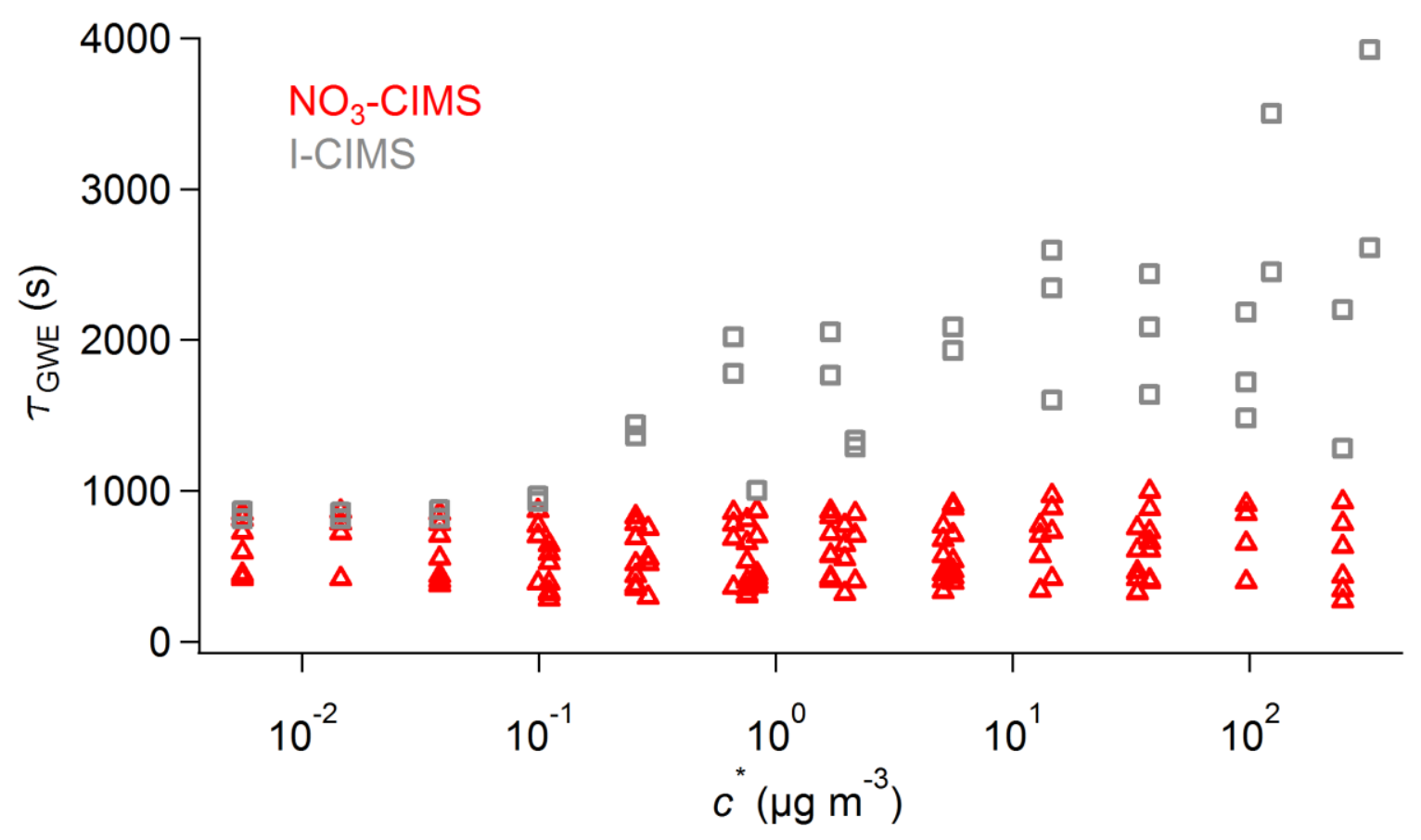

Figure S8. Equilibrium timescale $\left(\tau_{G W E}\right)$ vs. estimated $c^{*}$ for all of the wall loss measurements in this study, colored by CIMS ionization source. This figure gives an indication of the experimentto-experiment variability, as well as longer apparent timescales in I-CIMS measurements of higher volatility species $\left(c^{*}>0.1 \mu \mathrm{g} \mathrm{m}^{-3}\right)$, which are thought to be due to wall interactions (adsorption followed by slow re-evaporation) in the inlet line and ion source. 


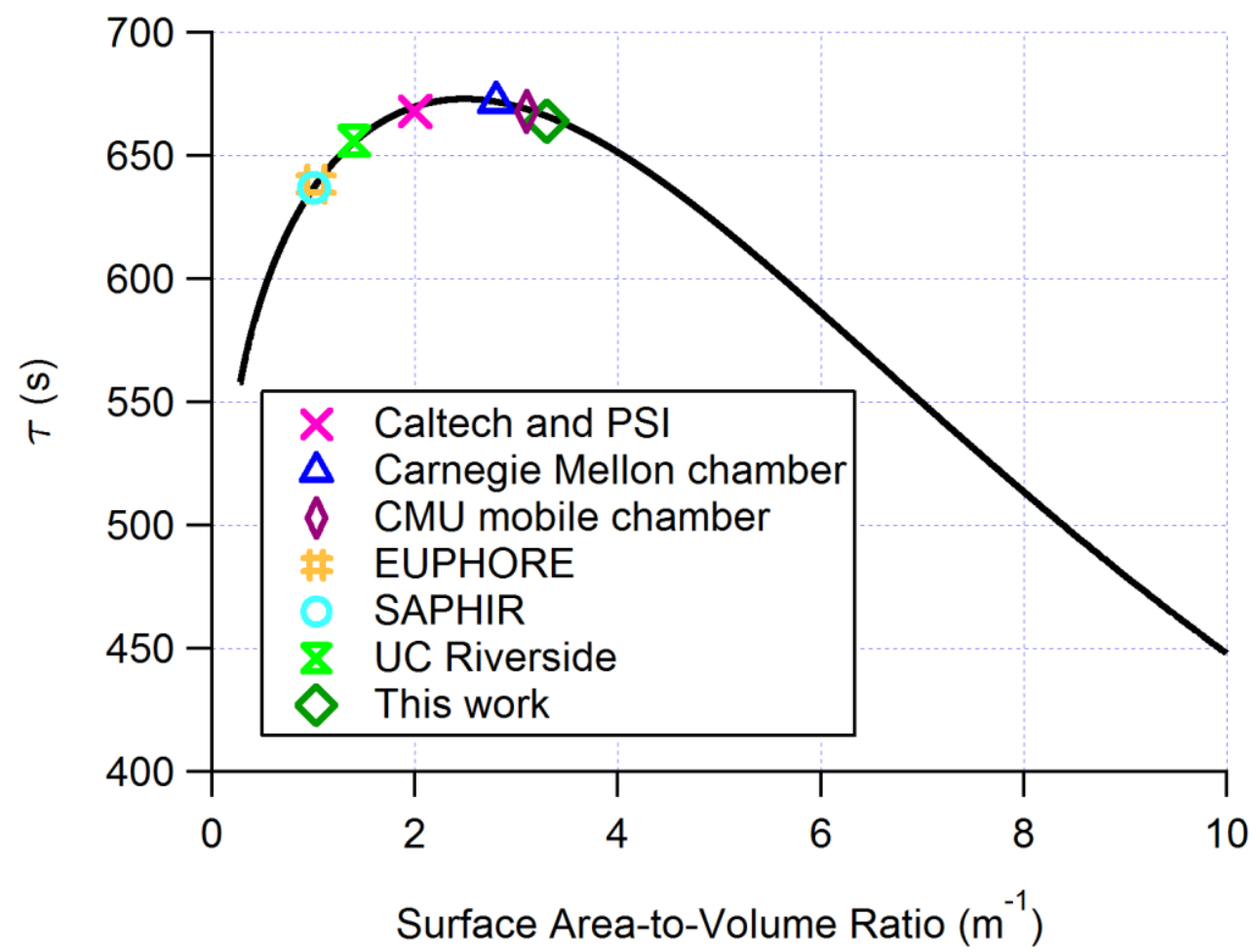

Figure S9: Estimated wall condensation timescale versus chamber surface-area-to-volume ratio $(\mathrm{A} / \mathrm{V})$ for a various chamber sizes using the equations in Table 1. 


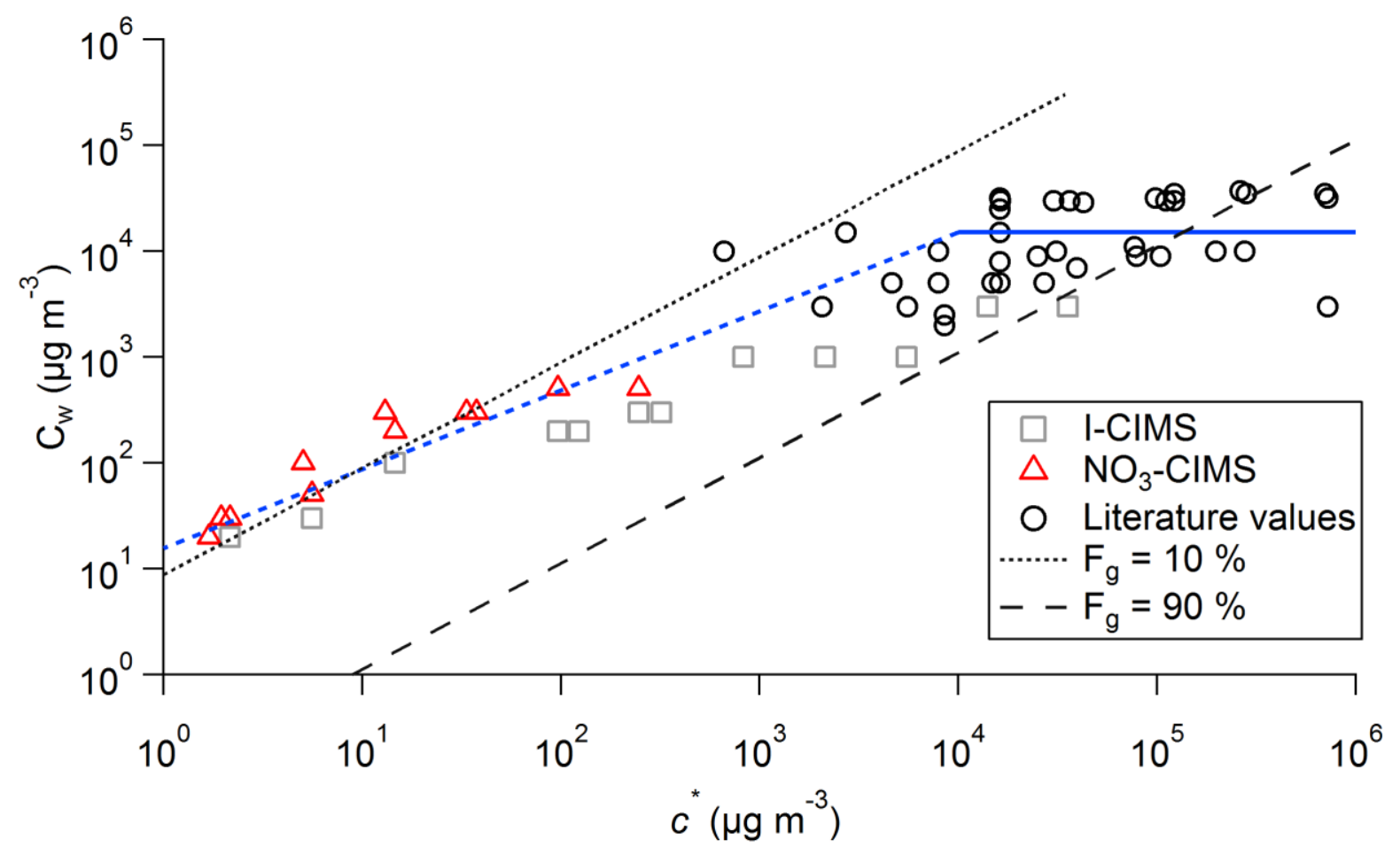

Figure S10: Average equivalent wall mass concentration $\left(C_{w}\right)$ values for measured species in this work, as determined by both CIMS techniques, and previously reported values from the Ziemann Group ${ }^{3,10,11}$ as a function of $c^{*} . C_{w}$ values could not be reliably determined in this work for species with $c^{*}<1$, as $F_{g}$ values in Figure 4 are close to zero. A piecewise function is provided to parameterize this dependence on the simulation of chamber experiments (equations shown in Table 1). $c^{*}$ values are estimated from SIMPOL ${ }^{12}$, and we recommend that SIMPOL is used as well before applying our parameterization to any species. Note that the I-CIMS values are thought to be biased low (see main text) and are shown by reference, but not used to determine the fits. 


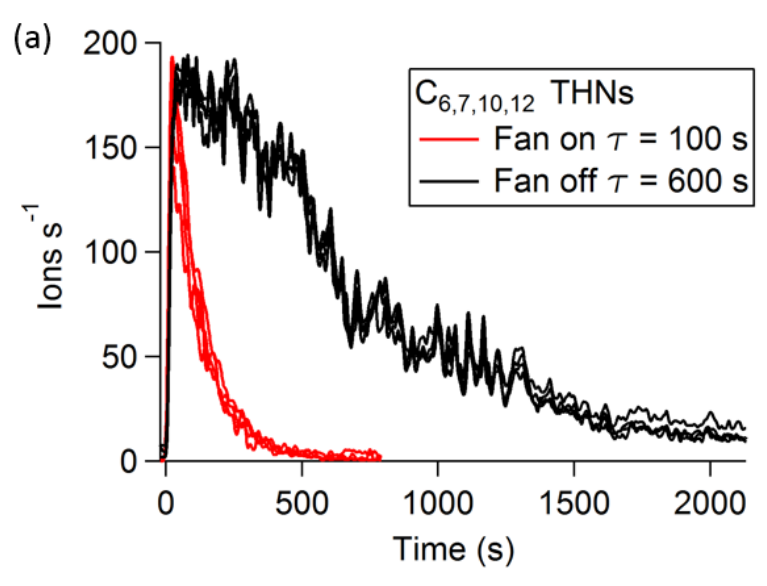

(b)
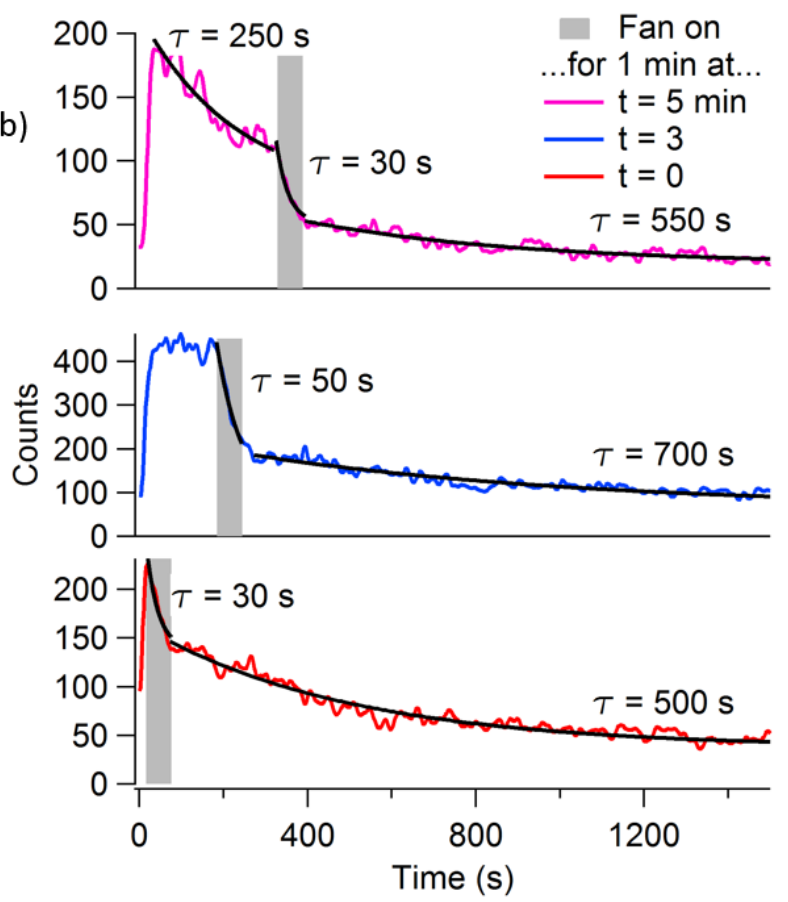

Figure S11: (a) Time series for select THNs in two separate wall loss bursts: one in which the fan was left on for the experiment duration and one in which it was off for the duration. (b) Averaged time series for several DHNs in three different bursts in which the fan was turned on for 1 minute either 0, 3, or 5 minutes into the experiment. Exponential fits were applied to each of the three time periods in the burst: when before the fan, during the fan, and after the fan. 


\begin{tabular}{|c|c|c|c|c|c|c|c|c|}
\hline No. & $\begin{array}{c}\text { HC } \\
\text { Precursor(s) }\end{array}$ & {$[\mathrm{HC}]$} & $\begin{array}{l}{[\mathrm{NO}]} \\
(\mathrm{ppm})\end{array}$ & $\begin{array}{l}\text { [MeNO2] } \\
\quad(\mathbf{p p m})\end{array}$ & $\begin{array}{l}\text { Reagent } \\
\text { Ion }\end{array}$ & $\begin{array}{c}\text { Line } \\
\text { Length }\end{array}$ & $\begin{array}{c}\text { Light } \\
\text { Burst } \\
\text { Duration }\end{array}$ & Other \\
\hline 1 & $\begin{array}{l}\text { 1-Alkanols: } \mathrm{C}_{6} \text {, } \\
\mathrm{C}_{8}, \mathrm{C}_{10}, \mathrm{C}_{12}\end{array}$ & 2.1 & 2.9 & 2.8 & $\mathrm{NO}_{3}^{-}$ & $0.7 \mathrm{~m}$ & $10 \mathrm{~s}$ & \\
\hline 2 & $\begin{array}{l}\text { 1-Alkanols: } \mathrm{C}_{6} \text {, } \\
\mathrm{C}_{8}, \mathrm{C}_{10}, \mathrm{C}_{12}\end{array}$ & 0.9 & 3.3 & 2.7 & $\mathrm{NO}_{3}^{-}$ & $0.7 \mathrm{~m}$ & $10 \mathrm{~s}$ & \\
\hline 3 & $\begin{array}{l}\text { 1-Alkanols: } \mathrm{C}_{6^{-}} \\
\mathrm{C}_{12}\end{array}$ & 2.0 & 2.9 & 2.7 & $\mathrm{NO}_{3}^{-}$ & $0.7 \mathrm{~m}$ & $10 \mathrm{~s}$ & \\
\hline 4 & $\begin{array}{l}\text { 1-Alkanols: } \mathrm{C}_{6^{-}} \\
\mathrm{C}_{12}\end{array}$ & 1.9 & 3.0 & 2.8 & $\mathrm{NO}_{3}^{-}$ & Variable & $10 \mathrm{~s}$ & \\
\hline 5 & $\begin{array}{l}\text { 1-Alkanols: } \mathrm{C}_{6^{-}} \\
\mathrm{C}_{12}\end{array}$ & 2.0 & 3.3 & 2.9 & $\mathrm{I}^{-}$ & Variable & $10 \mathrm{~s}$ & \\
\hline 6 & $\begin{array}{l}\text { 1-Alkanols: } \mathrm{C}_{6^{-}} \\
\mathrm{C}_{12}\end{array}$ & 2.0 & 3.2 & 2.6 & $\mathrm{I}^{-}$ & $0.7 \mathrm{~m}$ & $10 \mathrm{~s}$ & $>10 \mathrm{hr}$ \\
\hline 7 & $\begin{array}{l}\text { 1-Alkanols: } \mathrm{C}_{6^{-}} \\
\mathrm{C}_{12}\end{array}$ & 2.0 & 3.1 & 2.7 & $\mathrm{I}^{-}$ & $0.7 \mathrm{~m}$ & $10 \mathrm{~s}$ & $\begin{array}{l}\text { Long experiment; open } \\
\text { holes in bag to test leak } \\
\text { hypothesis }\end{array}$ \\
\hline 8 & $\begin{array}{l}\text { 1-Alcohols: } \mathrm{C}_{6} \text {, } \\
\mathrm{C}_{8}, \mathrm{C}_{10}, \mathrm{C}_{12}\end{array}$ & 0.05 & 3.1 & 0.35 & $\mathrm{I}^{-}$ & $0.7 \mathrm{~m}$ & $1 \mathrm{hr}$ & $\begin{array}{c}>20 \mathrm{hr} \\
\text { Long oxidation time }\end{array}$ \\
\hline
\end{tabular}

Table S1. Summary of relevant conditions under which some experiments were performed. Multiple wall loss measurements were obtained for many of the experiments. 


\begin{tabular}{|c|c|c|c|c|c|c|}
\hline $\begin{array}{c}\text { Compound } \\
\text { Class } \\
\end{array}$ & Formula & MW & $\begin{array}{l}\mathrm{NO}_{3}{ }^{-} \\
\mathrm{MW}\end{array}$ & $\begin{array}{c}\mathbf{I}^{-} \\
\mathbf{M W}\end{array}$ & Precursor & $\begin{array}{c}\operatorname{SIMPOL} c^{*} \\
\left(\mu \mathrm{g} \mathrm{m}^{-3}\right)\end{array}$ \\
\hline DHCN & $\mathrm{C}_{6} \mathrm{H}_{11} \mathrm{NO}_{6}$ & 193 & 255 & 320 & Hexanol & $3.34 \mathrm{E}+01$ \\
\hline DHCN & $\mathrm{C}_{7} \mathrm{H}_{13} \mathrm{NO}_{6}$ & 207 & 269 & 334 & Heptanol & $1.30 \mathrm{E}+01$ \\
\hline DHCN & $\mathrm{C}_{8} \mathrm{H}_{15} \mathrm{NO}_{6}$ & 221 & 283 & 348 & Octanol & $5.05 \mathrm{E}+00$ \\
\hline DHCN & $\mathrm{C}_{9} \mathrm{H}_{17} \mathrm{NO}_{6}$ & 235 & 297 & 362 & Nonanol & $1.95 \mathrm{E}+00$ \\
\hline DHCN & $\mathrm{C}_{10} \mathrm{H}_{19} \mathrm{NO}_{6}$ & 249 & 311 & 376 & Decanol & $7.50 \mathrm{E}-01$ \\
\hline DHCN & $\mathrm{C}_{11} \mathrm{H}_{21} \mathrm{NO}_{6}$ & 263 & 325 & 390 & Undecanol & $2.88 \mathrm{E}-01$ \\
\hline DHCN & $\mathrm{C}_{12} \mathrm{H}_{23} \mathrm{NO}_{6}$ & 277 & 339 & 404 & Dodecanol & 1.10E-01 \\
\hline DHN & $\mathrm{C}_{6} \mathrm{H}_{13} \mathrm{NO}_{5}$ & 179 & 241 & 306 & Hexanol & $2.46 \mathrm{E}+02$ \\
\hline DHN & $\mathrm{C}_{7} \mathrm{H}_{15} \mathrm{NO}_{5}$ & 193 & 255 & 320 & Heptanol & $9.65 \mathrm{E}+01$ \\
\hline DHN & $\mathrm{C}_{8} \mathrm{H}_{17} \mathrm{NO}_{5}$ & 207 & 269 & 334 & Octanol & $3.76 \mathrm{E}+01$ \\
\hline DHN & $\mathrm{C}_{9} \mathrm{H}_{19} \mathrm{NO}_{5}$ & 221 & 283 & 348 & Nonanol & $1.46 \mathrm{E}+01$ \\
\hline DHN & $\mathrm{C}_{10} \mathrm{H}_{21} \mathrm{NO}_{5}$ & 235 & 297 & 362 & Decanol & $5.57 \mathrm{E}+00$ \\
\hline DHN & $\mathrm{C}_{11} \mathrm{H}_{23} \mathrm{NO}_{5}$ & 249 & 311 & 376 & Undecanol & $2.16 \mathrm{E}+00$ \\
\hline DHN & $\mathrm{C}_{12} \mathrm{H}_{25} \mathrm{NO}_{5}$ & 263 & 325 & 390 & Dodecanol & $8.29 \mathrm{E}-01$ \\
\hline THN & $\mathrm{C}_{6} \mathrm{H}_{13} \mathrm{NO}_{6}$ & 195 & 257 & 322 & Hexanol & $1.69 \mathrm{E}+00$ \\
\hline THN & $\mathrm{C}_{7} \mathrm{H}_{15} \mathrm{NO}_{6}$ & 209 & 271 & 336 & Heptanol & $6.59 \mathrm{E}-01$ \\
\hline THN & $\mathrm{C}_{8} \mathrm{H}_{17} \mathrm{NO}_{6}$ & 223 & 285 & 350 & Octanol & $2.55 \mathrm{E}-01$ \\
\hline THN & $\mathrm{C}_{9} \mathrm{H}_{19} \mathrm{NO}_{6}$ & 237 & 299 & 364 & Nonanol & $9.85 \mathrm{E}-02$ \\
\hline THN & $\mathrm{C}_{10} \mathrm{H}_{21} \mathrm{NO}_{6}$ & 251 & 313 & 378 & Decanol & 3.79E-02 \\
\hline THN & $\mathrm{C}_{11} \mathrm{H}_{23} \mathrm{NO}_{6}$ & 265 & 327 & 392 & Undecanol & $1.45 \mathrm{E}-02$ \\
\hline THN & $\mathrm{C}_{12} \mathrm{H}_{25} \mathrm{NO}_{6}$ & 279 & 341 & 406 & Dodecanol & $5.55 \mathrm{E}-03$ \\
\hline $\mathrm{HN}$ & $\mathrm{C}_{6} \mathrm{H}_{13} \mathrm{NO}_{4}$ & 163 & 225 & 290 & Hexanol & $3.56 \mathrm{E}+04$ \\
\hline $\mathrm{HN}$ & $\mathrm{C}_{7} \mathrm{H}_{15} \mathrm{NO}_{4}$ & 177 & 239 & 304 & Heptanol & $1.40 \mathrm{E}+04$ \\
\hline $\mathrm{HN}$ & $\mathrm{C}_{8} \mathrm{H}_{17} \mathrm{NO}_{4}$ & 191 & 253 & 318 & Octanol & $5.49 \mathrm{E}+03$ \\
\hline $\mathrm{HN}$ & $\mathrm{C}_{9} \mathrm{H}_{19} \mathrm{NO}_{4}$ & 205 & 267 & 332 & Nonanol & $2.14 \mathrm{E}+03$ \\
\hline $\mathrm{HN}$ & $\mathrm{C}_{10} \mathrm{H}_{21} \mathrm{NO}_{4}$ & 219 & 281 & 346 & Decanol & $8.30 \mathrm{E}+02$ \\
\hline $\mathrm{HN}$ & $\mathrm{C}_{11} \mathrm{H}_{23} \mathrm{NO}_{4}$ & 233 & 295 & 360 & Undecanol & $3.21 \mathrm{E}+02$ \\
\hline $\mathrm{HN}$ & $\mathrm{C}_{12} \mathrm{H}_{25} \mathrm{NO}_{4}$ & 247 & 309 & 374 & Dodecanol & $1.23 \mathrm{E}+02$ \\
\hline
\end{tabular}

Table S2. Formulas, molecular weights, detected ion masses for both the $\mathrm{I}^{-}$and $\mathrm{NO}_{3}{ }^{-}$ionization techniques, alkanol precursor, and estimated saturation concentration for all detected oxidation products. The functional group composition of each molecule is given in the first column, where $\mathrm{DHCN}=$ dihydrox $y$ carbonylnitrate, $\mathrm{DHN}=$ dihydroxynitrate, $\mathrm{THN}=$ trihydroxynitrate, and $\mathrm{HN}=$ hydroxynitrate. 


\section{References}

(1) McMurry, P. H.; Grosjean, D. Gas and aerosol wall losses in Teflon film smog chambers. Environ. Sci. Technol. 1985, 19, 1176-1182.

(2) Palm, B. B.; Campuzano-Jost, P.; Ortega, A. M.; Day, D. A.; Kaser, L.; Jud, W.; Karl, T.; Hansel, A.; Hunter, J. F.; Cross, E. S.; et al. In situ secondary organic aerosol formation from ambient pine forest air using an oxidation flow reactor. Atmos. Chem. Phys. Discuss. 2015, 15, 30409-30471.

(3) Matsunaga, A.; Ziemann, P. J. Gas-Wall partitioning of organic compounds in a Teflon film chamber and potential effects on reaction product and aerosol yield measurements. Aerosol Sci. Technol. 2010, 44, 881-892.

(4) Boedeker. PTFE, FEP, and PFA Specifications http://www.boedeker.com/feppfa_p.htm (accessed Feb 1, 2016).

(5) Kuwata, M.; Zorn, S. R.; Martin, S. T. Using Elemental Ratios to Predict the Density of Organic Material Composed of Carbon, Hydrogen, and Oxygen. Environ. Sci. Technol. 2012, 46, 787-794.

(6) Brockmann, J. E. Sampling and transport of aerosols. In Aerosol measurement: Principles, Techniques, and Applications; Baron, P. A.; Willeke, K., Eds.; Wiley-Interscience: New York, 2001; pp. 143-195.

(7) Hilal, S. H.; Karickhoff, S. W.; Carreira, L. A. Prediction of the Vapor Pressure Boiling Point, Heat of Vaporization and Diffusion Coefficient of Organic Compounds. QSAR Comb. Sci. 2003, 22, 565-574.

(8) Hilal, S. H.; Saravanaraj, A. N.; Whiteside, T.; Carreira, L. A. Calculating physical properties of organic compounds for environmental modeling from molecular structure. $J$. Comput. Aided. Mol. Des. 2007, 21, 693-708.

(9) Krechmer, J. E.; Coggon, M. M.; Massoli, P.; Nguyen, T. B.; Crounse, J. D.; Hu, W.; Day, D. A.; Tyndall, G. S.; Henze, D. K.; Rivera-Rios, J. C.; et al. Formation of low volatility organic compounds and secondary organic aerosol from isoprene hydroxyhydroperoxide low-NO oxidation. Environ. Sci. Technol. 2015, 49, 10330-10339.

(10) Yeh, G. K.; Ziemann, P. J. Gas-Wall partitioning of oxygenated organic compounds: measurements, structure-activity relationships, and correlation with gas chromatographic retention factor. Aerosol Sci. Technol. 2015, 49, 726-737.

(11) Yeh, G. K.; Ziemann, P. J. Alkyl nitrate formation from the reactions of C8 -C14 n alkanes with $\mathrm{OH}$ radicals in the presence of $\mathrm{NOx}$ : measured yields with essential corrections for gas-wall partitioning. J. Phys. Chem. A 2014, 118, 8147-8157.

(12) Pankow, J. F.; Asher, W. E. SIMPOL.1: a simple group contribution method for predicting vapor pressures and enthalpies of vaporization of multifunctional organic compounds. Atmos. Chem. Phys. 2008, 8, 2773-2796. 